$=$

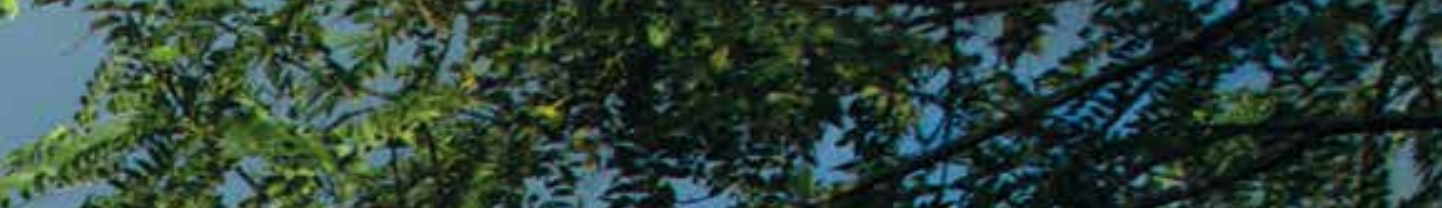

.

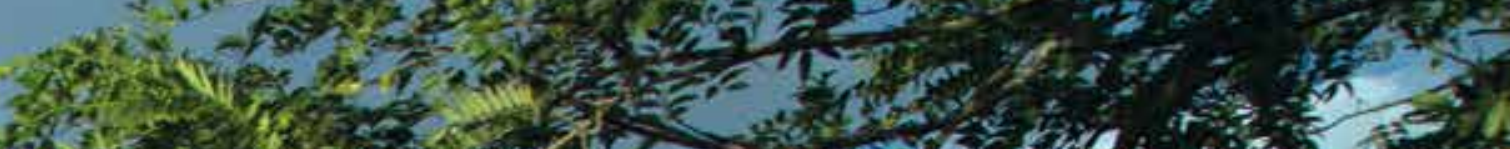

at,

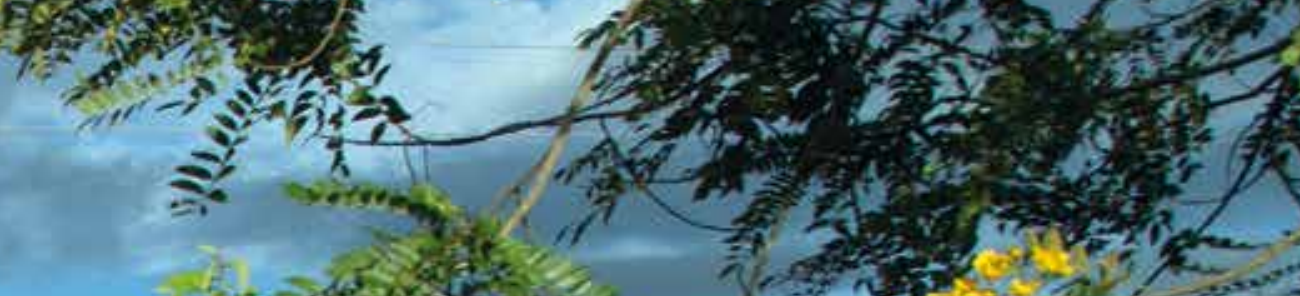

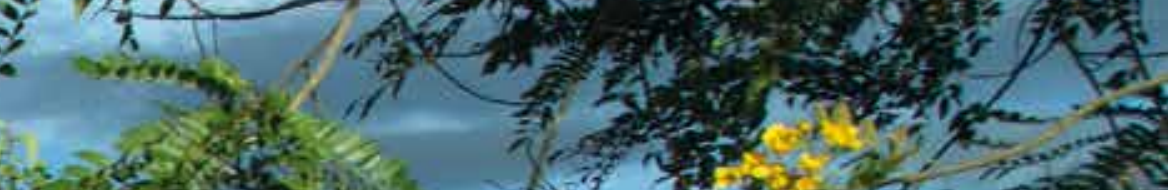
-

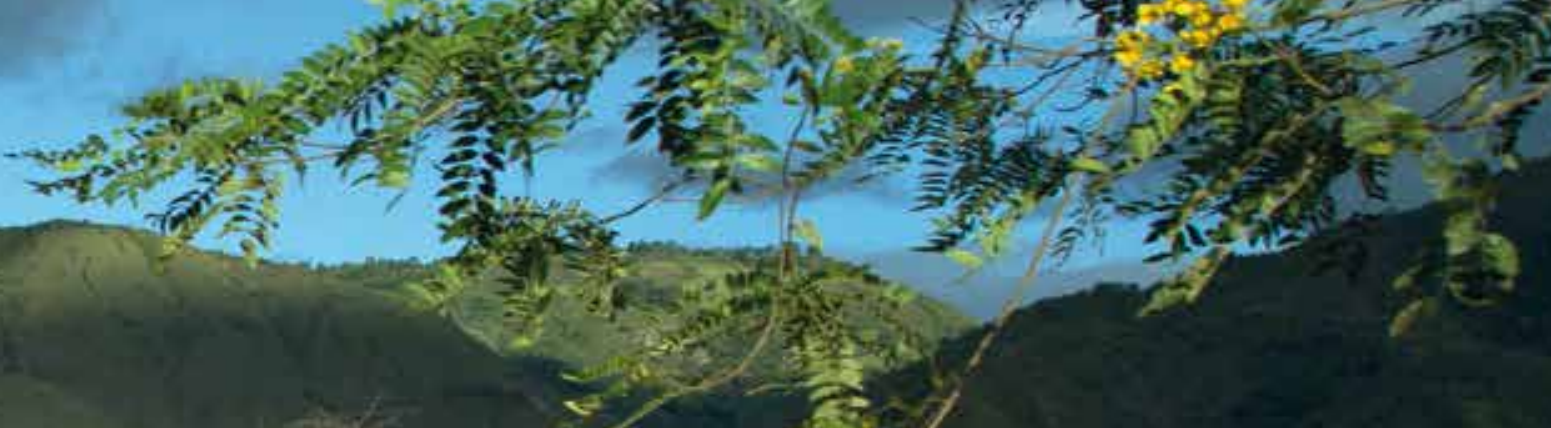

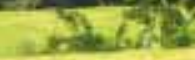

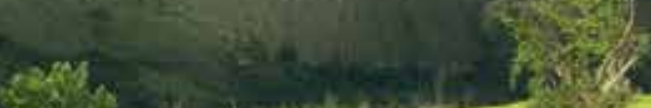

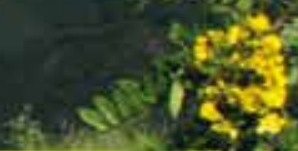

somady

$x \leq y$

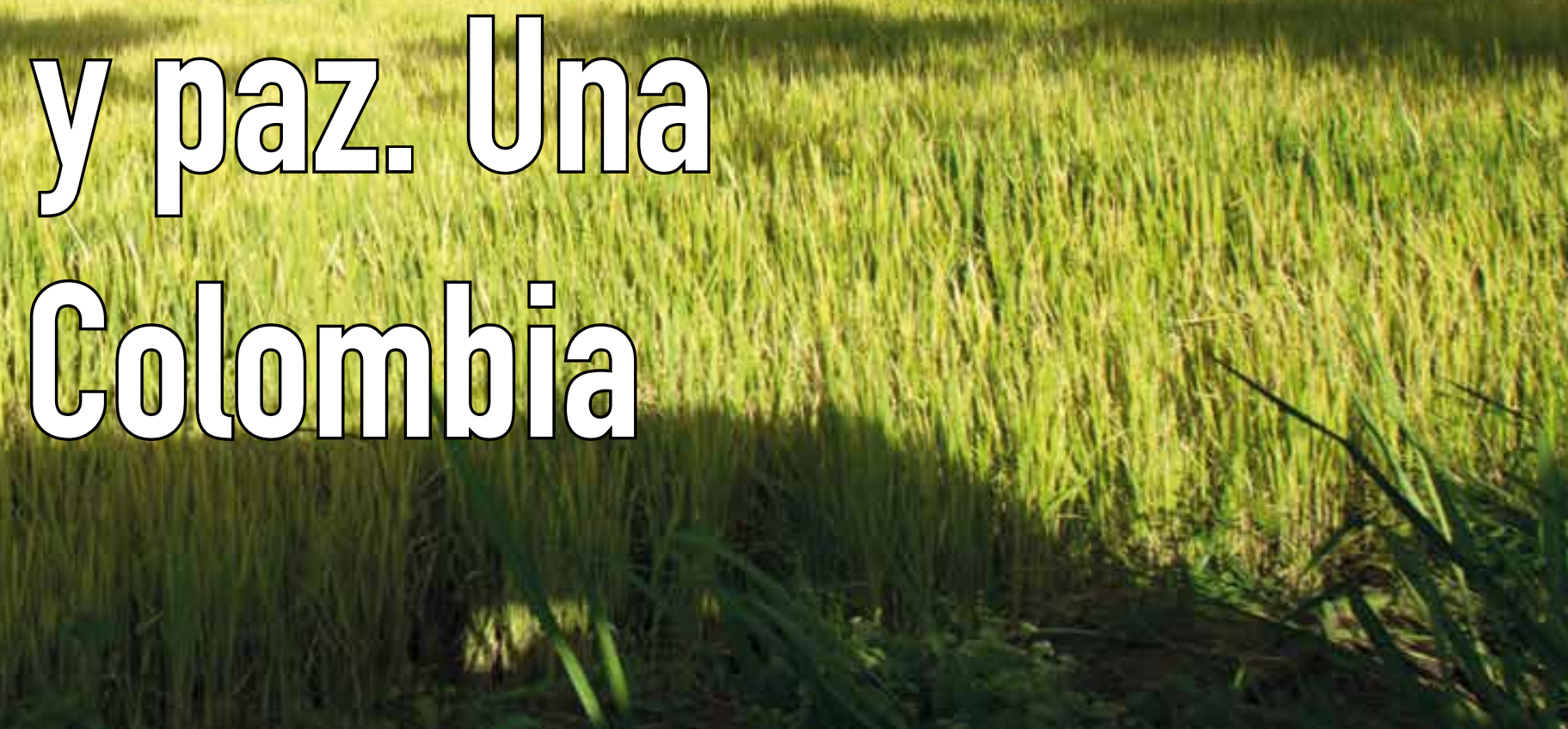




\section{De imágenes, sentido y paz. Una esperanza llamada Colombia}

\section{Verónica Vázquez-Cangas}

\author{
Un sentido no puede ser más que esencialmente otro.
} Jean Luc Nancy (Biblioteca Vasconcelos, 2015). ${ }^{1}$

\section{Resumen}

El momento histórico que vive Colombia muestra la pertinencia de reflexionar sobre los posibles derroteros de una educación que, a través del establecimiento de una relación con el arte, visto desde la perspectiva de la imposibilidad humana para no crear imágenes, construya un futuro distinto para las nuevas generaciones. Con el pensamiento de Freud y María Montessori como referencias privilegiadas para bordear el significado de la violencia y sus consecuencias, en lo colectivo, pero también en lo individual; de uno por uno en su singularidad, se proponen algunas líneas de análisis y práctica educativa, cuyo origen se sitúa en las particularidades de la realidad de los niños y jóvenes en edad escolar, afectados por la violencia y sus secuelas; en la necesidad de los ciudadanos de elaborar el duelo por las pérdidas sufridas y en la apertura de Colombia al mundo, a fin de dar lugar al arte en la búsqueda de la resignificación y la construcción de sentido. Un esfuerzo tal podría encontrar importantes resonancias en otros países atravesados por la violencia, creando así alternativas distintas, donde se incluya todo lo otro, de lo que también forma parte la relación de la especie humana con el planeta.

Palabras clave: otro, imagen, educación, danza, paz, arte.

1 Frase tomada de Biblioteca Vasconcelos (2015). Traducción propia.
Of Images, Meaning, and Peace. A Hope Called Colombia

\begin{abstract}
Colombia is living a historical moment, which shows the relevance of deliberating on the possible courses of an education which, through its relationship with art, as seen from the perspective of the human impossibility to not create images, builds a different future for new generations. Taking Freud's and Maria Montessori's thoughts as privileged references in order to examine the meaning of violence and its consequences, at both collective and individual levels, considering them one by one in their singularity, this article proposes lines of analysis and educational practice, whose origin lies in the specific reality of children and young students, who are affected by violence and its sequels; in the need of the citizens to mourn their losses, and in Colombia's opening to the world, in order to give place to art in the search for the re-signification and creation of meaning. Such an effort might find strong echoes in other countries who suffer from violence, creating new alternatives to include the other, which includes as well the relationship of human beings to the planet.
\end{abstract}

Keywords: other; image; education; dance; peace; art.

\section{De imagens, sentido e paz. Uma esperança chamada Colômbia}

\section{Resumo}

O momento histórico que vive Colômbia mostra a pertinência de refletir sobre os possíveis trajetos que uma educação que, por meio do estabelecimento de uma relaçáo com a arte, enxergado desde a perspectiva da impossibilidade humana para náo criar imagens, construa um futuro distinto para as novas geraçôes. Com o pensamento de Freud e Maria Montessori como referentes privilegiados para bordar o significado da violência e suas consequências, no coletivo, mas também no individual; de um por um em sua singularidade, propóem-se algumas linhas analíticas e de pratica educativa, cuja origem se situa nas particularidades da realidade das crianças e jovens em idade escolar, afetados pela violência e suas sequelas; na necessidade dos cidadáos de fazer um duelo pelas perdidas sofridas e em a apertura da Colômbia ao mundo, com o sentido de dar lugar à arte na procura da re-significação e a construção de sentido. Um esforço assim poderia achar importantes ressonâncias em outros países atravessados pela violência, criando assim alternativas distintas, onde se inclua tudo o outro, do que também forma parte a relação da espécie humana com o planeta.

Palavras chave: outro, imagem, educação, dança, paz, arte. 
En un momento tan deseado como temido, Colombia enfrentó una decisión histórica: los ciudadanos se pronunciaron sobre el acuerdo de paz negociado entre el gobierno y la guerrilla. El sentido de los resultados, donde el abstencionismo fue la fuerza más elocuente, revela la urgencia ineludible de trazar caminos que podrían dar paso a un futuro distinto, entre ellos, el de educar con la paz como horizonte y el arte, como rosa de los vientos. ¿A qué paz se alude entonces? ¿A la paz interior que solo se consigue con el tiempo, la autocrítica, la reflexión y el reconocimiento de que yo es otro ${ }^{2}$ ? ¿A la paz entre grupos sociales cuyas semejanzas y diferencias los conducen a diversas acciones violentas, estratégicas o improvisadas, más o menos duraderas, pero siempre excesivas en sangre y crueldad?

Ante la idea de ambos registros surgen dos nombres: Sigmund Freud y Maria Montessori. No es una asociación caprichosa, de hecho el reconocimiento que el primero expresó a la labor pedagógica de la segunda, es bien conocido (citado por Ruiz, 2012).

Montessori retoma en su trabajo lo inconsciente, lo afirma y construye una noción propia en torno al descubrimiento de Freud y, sin embargo, se interrumpe, abandonando el camino que en algún momento estuvo dispuesta a recorrer, en pos de los enrevesamientos de la psique. Esta interrupción es, cuando menos, notable desde la perspectiva pedagógica. Ante ella asoma una inquietante pregunta: ¿Qué irrumpió en la práctica/relación con los niños en la trayectoria de Montessori, para consolidarla hacia destinos más amables y risueńos como la seguridad del matiz espiritual y religioso? Este interrogante también se extiende al devenir del pensamiento pedagógico y su muy frecuente negación del impacto potencial del psicoanálisis, en la construcción de opciones educativas. La esperanza de encontrar un cruce riguroso que reoriente al primero se antoja, entonces, ilusoria.

\section{Freud, Montessori y la guerra}

Además de la pasión por algo que podría denominarse humano, Freud y Montessori compartieron un tramo de la historia que constituyó un parteaguas del que no hubo camino de regreso. La civilización occidental, su cultura, no ha podido ni podrá recuperarse nunca. Ciertamente no en la lógica de Adorno, cuando sentenció la imposibilidad de la poesía después de Auschwitz ${ }^{3}$, pero las pérdidas asociadas a lo que esa etapa reveló e inauguró siguen resonando y diseminando consecuencias que, a veces, se tornan casi innominables. Lejos de las esperanzas de Montessori y Freud, expresadas cada uno por su lado, la civilización no ha garantizado una vida mínimamente digna ${ }^{4}$ para la mayor parte de los humanos. Al contrario, ha sido la creatura que condena progresivamente a una mayoría creciente e indemne, a una esclavitud asociada a mercados que rebasan cualquier frontera y posibilidad de control, así como a una degradación profunda del planeta, llevada a un punto tal que, según los especialistas, ya no hay manera de frenar y, mucho menos, de revertir. ${ }^{5}$

Freud (1915) escribe:

[...] podía suponerse que los grandes pueblos, como tales, habían alcanzado un entendimiento suficiente acerca de su patrimonio común y una tolerancia tal hacia sus diferencias que "extranjero" y "enemigo" ya no podrían confundirse en un solo concepto, como aún ocurría en la antigüedad clásica (p. 278).

Este orden de ideas conduciría a la imposibilidad de imaginar al compatriota como enemigo potencial. El conflicto en Colombia remite entonces al fratricidio: no pasa por la identidad nacional, ni por la lengua o la cultura, pero sí por el territorio. Deja escuchar ecos del relato de Caín y Abel, choque fundacional.

A nivel de la eticidad individual, Freud (1915) continúa:

[...] ha de estar en juego un proceso de desarrollo, y sin duda supondrá que este consiste en lo siguiente: las malas inclinaciones del hombre le son desarraigadas y, bajo la influencia de la educación y del medio cultural, son sustituidas por inclinaciones a hacer el bien (p. 282). Y, sin embargo, después de un análisis sobre el desarrollo pulsional que la cultura o la capacidad que esta demanda, él mismo concluye:

2 Esta frase sintetiza una posible lectura de El estadio del espejo, de Jacques Lacan.

3 "Escribir poesía después de Auschwitz es un acto de barbarie". Sin embargo, Adorno encuentra en el pensamiento, un camino que no abandonará (citado por Matamoro, 2003).

4 Por dignidad, término muy socorrido en los discursos contemporáneos, estoy entendiendo que todo ciudadano tenga acceso a: servicios de salud y educación asequibles y de calidad; vivienda donde esté disponible la energía eléctrica, agua potable, señal de internet, drenaje; oportunidades laborales en condiciones de seguridad y remuneración satisfactorias; respeto a sus derechos y a una representación congruente con sus intereses; seguridad en todos sentidos y libertad de expresión, entre otros indicadores.

5 Para designar este hecho se acuñó el término ecocidio y se propuso tipificarlo como el quinto crimen contra la paz dentro del Estatuto de Roma, pero fue anulado en 1996, en un gesto que parecería decir: "si no lo nombramos, no existe" (Claramonte, 2013). 
En suma, erramos juzgando a los hombres "mejores" de lo que en realidad son [...]. La educación y el medio no solo tienen premios de amor por ofrecer; trabajan también con otra clase de premios de conveniencia: recompensas y castigos. Por tanto, su efecto puede ser que el sometido a su influencia se decida por la acción culturalmente buena sin haber consumado dentro de sí un ennoblecimiento pulsional, una transposición de inclinaciones egoístas a inclinaciones sociales [...]. La sociedad de cultura, que promueve la acción buena y no hace caso de su fundamento pulsional, ha conseguido así obediencia para la cultura en un gran número de hombres que en eso no obedecen a su naturaleza, [...] la afrenta y la dolorosa desilusión que experimentamos por la conducta inculta de nuestros conciudadanos del mundo en la presente guerra, no estaban justificadas. Descansaban en una ilusión de la que éramos prisioneros. En realidad, no cayeron tan bajo como temíamos, porque nunca se habían elevado tanto como creímos (Freud, 1915, pp. 284-286).

Desde su propio discurso, Montessori (citada por Ortega, 2006) plantea una posición similar a la de Freud: "La primera línea verdadera de defensa contra la guerra es el hombre mismo, y ahí donde el hombre esté socialmente desorganizado y desvalorizado, por esa brecha se introducirá el enemigo universal” (p. 270).

La divisa de la educación montessoriana es gracia y cortesía. En estas dos palabras se decanta algo que no forma parte de las competencias socioafectivas contemporáneas, sino de nociones propias del conocimiento histórico, intuitivo y sistematizado de lo que los humanos pueden alcanzar. Eso a lo que los griegos llamaban sophrosyne: "Desde

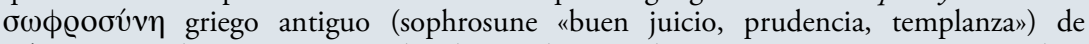

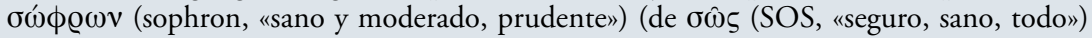

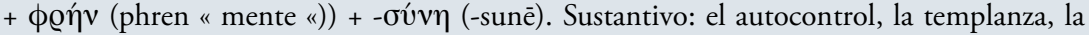

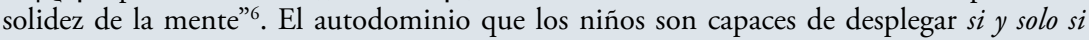
no son violentados por los adultos, sino protegidos y respetados, tiene como correlato una relación de respeto y acogida hacia el otro ${ }^{7}$. La ambición era, naturalmente para esta escuela, construir una educación para la paz:

La historia humana nos enseña que paz significa la sumisión forzosa de los conquistados a la dominación cuando el invasor ha consolidado su victoria, la pérdida de todo lo que estiman los vencidos, y el fin del placer de disfrutar los frutos de su trabajo y sus conquistas. Los vencidos se ven forzados a realizar sacrificios, como si fueran los únicos culpables y merecieran ser castigados simplemente por haber sido vencidos. Mientras tanto, los vencedores hacen alarde de los derechos que sienten que les corresponden por haber ganado al pueblo derrotado, la verdadera víctima del desastre. Esas condiciones quizás marquen el final del combate, pero no hay duda de que no pueden recibir el nombre de paz (Ortega, 2006, p. 271).

Entonces y hasta ahora, paz y armonía no son correlativas ni contiguas. Una gran mayoría de los sobrevivientes de las guerras contemporáneas terminan siendo víctimas, aunque se perciban como vencedores que, como lo describe Montessori, tendrán que encontrar la manera de vivir con lo que la historia nos ha enseńado a llamar derrota/costoasociado-a-la-seguridad, ocultando consecuentemente el rencor y el ansia de venganza inherentes, mismas que parecen correr en la sangre como uno de sus elementos constitutivos, clamando con la fuerza de una invocación: "Los dioses son indiferentes a las plegarias, pero cuando huelen sangre, se asoman a mirar" (Hubard, 2006, p. 42). Ante la contundencia de lo que ha sido separado, destrozado, hay quienes llaman a la reconciliación, al perdón. Para muchos, un perdón simplemente impensable, inadmisible e indigno.

\section{Discurso pedagógico y realidad escolar. Crónica de un desencuentro}

En un movimiento inverso, Freud y Montessori llevaron a cabo su obra a partir de la singularidad, de humanos específicos. El objeto de sus preguntas no era algo dado, conocido en el sentido de agotable, y siempre igual. La educación contemporánea, en contraste, formula características comunes a todos sus sujetos y, por tanto, mensurables, manejables y gestionables. $\mathrm{Al}$ recibir las consignas de lo que las nuevas generaciones deben aprender, cabe preguntarse: ¿De qué mundo están hablando?

El panorama no podría -casi-ser más ominoso. Específicamente en el de la educación que se ha armado de estándares y artefactos para la uniformidad que, como las fuerzas del mercado, traspasan fronteras, regiones y aplastan singularidades.

6 Tomado de Diccionario-internacional.com (http://diccionario-internacional.com/ definitions/?spanish_word=sophrosyne)

7 Desafortunadamente, una vez fuera del ambiente Montessori, el entorno dificulta el ejercicio de ambas maneras de relacionarse, por lo que muchos de sus egresados se refugian -sin declararlo ni planearlo- en una suerte de resistencia. 
Un recorrido por algunas de las escuelas de educación básica del sistema público mexicano obliga, entre otras cosas, a enfrentar las consecuencias del desencuentro entre el discurso pedagógico dominante y la realidad de los niños y jóvenes que asisten, o no, a aquellas. Entre las más arbitrarias, dolorosas e ininteligibles, por evidente y compleja, destaca la de los estudiantes que están vinculados - por parentesco, vecindad o amistad- a alguno o algunos de los millones de migrantes, desaparecidos o desplazados por razones políticas, económicas o de género, entre las más destacadas. Su extremo más atroz son los nińos sicarios.

Este panorama no es, sin duda, privativo de México. Los tráficos a todo lo largo y ancho de Latinoamérica han trazado relaciones de poder y una redistribución de la riqueza que profundizan aún más las condiciones de desigualdad en las que vive la población. El sufrimiento de los nińos y adolescentes mexicanos tocados por la violencia, cuyo impacto lo ha tornado en una condición, muy probablemente se replica en otras regiones del continente ${ }^{8}$, afectando no solo su desempeńo académico, sino la viabilidad de su futuro (El Espectador, 2016). Frente a esta realidad incontestable, el discurso pedagógico responde con clasificaciones para manejar los signos del sufrimiento, que están más allá de su interés, con designaciones como: rezago académico; deserción; barreras de aprendizaje; diagnósticos que llaman a la medicalización; pobre desempeño en las pruebas internacionales que miden la comprensión lectora y el pensamiento lógico matemático; entre otras. Estos rasgos son reconocidos por ese mismo sistema como situaciones a superar a fin de alcanzar su aspiración, la cual apunta a producir ciudadanos libres $\mathrm{y}$ responsables ${ }^{10}$, es decir, capaces de gestionar, en favor de la sociedad, sus propias vidas, a través de su inserción en los mercados laborales. Esta premisa ha detonado una dinámica relación entre las empresas presentes en cada región y las correspondientes instituciones de educación media superior y superior, de manera que su colaboración produzca los trabajadores/empleados/ emprendedores/consumidores/consumibles que las primeras demandan ${ }^{11}$.

Y las instituciones de educación pública responden, obedientes, a esta demanda, sin reparar en que, bien a bien, no se sabe lo que esas organizaciones requerirán en ¿̇cinco?, ¿diez años? $\mathrm{Ni}$ siquiera se puede asegurar que seguirán existiendo para esa fecha. Los empleos que muchos de los estudiantes, quienes cursan actualmente a nivel medio y superior, estarán desempeñando en ese futuro bastante próximo, aún no se inventan o están en proceso de creación. ¿Cómo adivinar entonces cuál deberá ser su perfil? Los sujetos para la organización en vez de la organización para los sujetos.

Ambas realidades carecen de punto de encuentro. ¿Por qué las máximas instancias internacionales como la Unesco o la misma OCDE no han reaccionado con un elemental sentido de urgencia ante las múltiples crisis humanitarias de mediados del siglo XX hasta la fecha, llevando a cabo intervenciones en las políticas públicas de educación, con base en la realidad descrita más arriba, a fin de prevenir su reincidencia?

Sin embargo, la paz, entendida como la posibilidad de convivencia respetuosa y con apego a las leyes que nos hemos estipulado para hacer posible un estado de bienestar que incluya a todos los integrantes de una sociedad dada, con perspectiva de futuro y ejercicio de la libertad, en el contexto de una cultura que valore y dé lugar a la expresión diversa e incluso discrepante, $\operatorname{dif}(i) r(i) e n t e$, donde resuenan diferir y herir, es necesaria para sostener la vida en nuestro planeta. ¿Qué implica conseguirla y mantenerla? ${ }^{12}$.

8 Esta premisa incluye a la primera potencia mundial, tal como lo atestigua la película Escritores de la libertad. Basada en hechos reales, la maestra Gruwel puso a la disposición de sus estudiantes, sin expectativas propias o del sistema, la literatura para resignificar su propia experiencia. Sinopsis en: http://paideiaula.jimdo.com/ $\mathrm{m} \% \mathrm{C} 3 \% \mathrm{~B} 3$ dulo-3-estrategias-metodol\%C3\%B3gicas/pel\%C3\%ADcula-el-diario-de-los-escritores-de-lalibertad/

9 En México, esta palabra llama inevitablemente a la desafortunada y lamentable convocatoria del presidente de la República, Enrique Peña Nieto, el 4 de diciembre de 2014, en una visita al estado de Guerrero: "Quiero convocarles para que con su capacidad, con su compromiso con su estado, con su comunidad, con sus propias familias, hagamos realmente un esfuerzo colectivo para que vayamos hacia adelante y podamos realmente superar este momento de dolor" (subrayado por fuera del texto original). Como ha sido una constante en su fallida comunicación, el presidente se equivoca al llamar a la desaparición forzada de los 43 estudiantes de Ayotzinapa, algo superable, cuando en realidad se trata del resultado de la acción intencional de las fuerzas policiacas y militares, en contubernio con el crimen organizado (Expansión.mx, 2014).

10 Aurelio Nuño, ministro de Educación en México, durante la presentación del Nuevo modelo educativo 2016.

11 La OCDE define el logro educativo como: "Tener una buena educación mejora en gran medida la probabilidad de encontrar empleo y de ganar suficiente dinero" (http://www.oecdbetterlifeindex.org/es/ topics/education-es/). En efecto, es posible que mejore la probabilidad, no la realidad de encontrar un empleo bien remunerado, como las tasas de desempleo entre personas con posgrados universitarios en muchos países de integrantes de este organismo, lo prueban, así como la creciente precariedad de las condiciones de trabajo. 12 La creación y mantenimiento de iniciativas para una educación incluyente en el terreno de conflicto como las escuelas Hand in Hand en Israel, ofrecen experiencias sustentables, así como el Parents Circle-Families Forum. Ver: https://www.handinhandk12.org/y http://www.theparentscircle.com/, respectivamente. Gracias a José Hamra por las referencias: http://espejoalfrente.blogspot.mx/ 


\section{El duelo, de uno en uno}

El ejemplo de Colombia, en el contexto actual, puede constituirse en el faro que ofrezca guía al resto de la humanidad, en esta era de inesperadas y enormes migraciones, de conflictos para los que la intervención humanitaria ${ }^{13}$ no ha sido respuesta, mucho menos causa de lo que se esperaba. Colombia, un país sumido en un conflicto armado que dio inicio, aproximadamente, entre 1946 y 1958 y cuya génesis se remonta, se dice, muchos años antes y de la mano de la penetración capitalista. El saldo oficial: 220.000 muertos y 5,3 millones de desplazados (Revista Semana, 2015). A diferencia de otros enfrentamientos entre países, confesiones religiosas, diferencias étnicas/raciales, en Colombia el enemigo es, a la vez, un compatriota, hecho que matiza dramáticamente la diferencia con otras realidades. En este sentido, la situación de México guarda muchas semejanzas.

¿Cómo traducir esas cifras en un número aproximado de deudos/dolientes de todas las edades, cuyas pérdidas alteraron su vida para siempre? Familias destrozadas, escuelas abandonadas, amores interrumpidos. ¿Cómo calcular la repercusión de un duelo sin nombrar, en niños en edad escolar, para su desarrollo y su capacidad de aprendizaje? "El duelo es, por regla general, la reacción frente a la pérdida de una persona amada o de una abstracción que haga sus veces, como la patria, la libertad, un ideal, etcétera" (Freud, 1917, p. 241). Dicha pérdida es un hecho. Terrible, devastadora, incomprensible, pero situable en el tiempo y el espacio. Cuando esa pérdida se anuda a sucesos vertiginosos, que desbordan la capacidad de aprehensión de los sujetos envueltos en ellos, ¡cómo darle un espacio, un nombre en la conciencia, en el transcurrir de la propia historia? ¿Cómo se llora al ausente, sin por lo menos poder ver su cuerpo exánime? ¿Cómo detener la obstinada esperanza de volver al hogar después de la devastación que causa la violencia? ¿Cómo impedir la añoranza del propio cuerpo, si se ha vuelto imposible retornar a su previo ser y estar, a causa de las heridas y mutilaciones sufridas? ¿Cómo habitar un cuerpo traspasado, invadido, torturado? ¿Cómo soltar ese lugar perdido, sin estar en él?

Una pérdida sin objeto, ni físico, ni descifrable. "Y tal vez hubiera sido mejor decir: un objeto visual que muestra la pérdida, la destrucción, la desaparición de los objetos o los

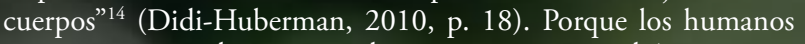
somos cuerpo, todo pasa por el cuerpo que es -simultáneamentecontinente y contenido. Ese objeto visual del que habla DidiHuberman, bien podría ser una tumba a la que llama la evidencia de un volumen, algo a lo que es posible asirse, depositario de la mirada que simultáneamente, devuelve:

[...] a saber, el destino del cuerpo semejante al mío, vaciado de su vida, de su palabra, de sus movimientos, de su poder de alzar los ojos hacia mí. Y que sin embargo en un sentido me mira -el sentido ineluctable de la pérdida aquí en obra- [...]. He aquí por qué la tumba, cuando la veo, me mira hasta lo más recóndito, [...] en la medida misma en que me muestra que he perdido ese cuerpo que recoge en su fondo (Didi-Huberman, 2010, pp. 19-20).

Como Antígona ante su padre, los sobrevivientes tal vez se pregunten: “¿Por qué has muerto, de este modo, sin mí?".

Por otro lado, está la experiencia de la pérdida cuyo único horizonte se encuentra en una demanda de justicia que, para serlo, debe tener el sabor de la venganza. Pero, ¿qué castigo podría resarcir el dolor infligido?; ¿qué condena devolvería la paz

13 La estrategia así llamada parece haber agotado sus posibilidades, como lo muestra el conflicto en Siria (Rieff, 2016).

14 Esta precisión que hace Didi-Huberman (2010) tiene que ver con la obra del artista estadounidense Jaspers Johns, cuya afirmación original era "An object that tells of loss, destruction, disappearence of objects" (un objeto que habla de la pérdida, de la destrucción, de la desaparición de los objetos). En ella asoma el poder del arte para descifrar o, mejor aún, ofrecer la posibilidad de aludir a lo irrepresentable. a los brazos que se llenan de vacío, a los ojos que de tanto mirar a la distancia, esperando el retorno del ser amado, han dejado de ver?; ¡es posible restituir la ausencia cuyo trazo se desdibuja lenta e irrefrenablemente, dejando al doliente todavía más solo?

Indudablemente, la impunidad no es una alternativa, así como la asunción de un acuerdo entre las partes no es sinónimo de perdón ni de olvido. Todo intento de acallar las voces de quienes reclaman que los agresores se plieguen a la sanción correspondiente y se sometan a un mínimo acto de expiación, es inadmisible. Pero cuando de educación se trata, es imperativo preguntarse: ¿Qué hay más allá?; ¿dónde buscar las representaciones/palabras/imágenes que nombren, por fin, los estragos sufridos y permitan así acotarlos, definirlos y construir la distancia indispensable para verlos desde otro lugar? Reaprehender la vida para posibilitar el aprendizaje.

\section{Vuelta a la página. La posibilidad de re-significar}

Jacques Derrida usaba la expresión "aprender a vivir, por fin":

Aprender a vivir es madurar, educar también [...]. Este suspiro se abre a una interrogación aún más difícil: vivir es algo que puede aprenderse, enseñarse? ¿Se puede aprender por disciplina o aprendizaje, por experiencia o experimentación a aceptar, o mejor, a afirmar la vida? (Derrida, 2014).

Este supuesto entrańa a la muerte. Se puede pensar la muerte de los otros, pero no la propia.

Después de un enfrentamiento tan largo, en el tiempo y la memoria, tal vez hay que empezar por sobrevivir, tanto en el sentido de permanecer, a pesar de la muerte y la destrucción, como en el de continuar. Es en este impulso esencial donde el arte sugiere un posible mapeo, que la vocación de apertura propia de Colombia hace más prometedor, exponiéndose como otro a quien interpelar en busca de nuevos/otros sentidos, así como volviéndose sobre cada uno, de uno en uno, porque son solo con los otros.

En Colombia, la creación ha continuado a pesar de la guerra, así como su economía e instituciones que, mejor o peor, han sostenido una democracia. Ahí están como ejemplo Gabriel García Márquez y muchos otros autores, entre los que se cuenta el grupo de la llamada novela de la violencia, o las sobrecogedoras puestas en escena, por su contenido y factura, creadas por Rolf Abderhalden con la compañía Mapa Teatro. Artistas plásticos de la talla de Edgar Negret, Luis Caballero, Ramírez Villamizar o el fenómeno que ha sido Fernando Botero, tan popular como Shakira y Juanes, y los no tan conocidos pero muy importantes Blas Atehortúa, Andrés Posadas y Sergio Mesa, entre otros.

En su país o fuera de él, el vínculo de los creadores colombianos con el miedo y el dolor y la reinvención, explícitos o no en su obra, ha dado lugar a expresiones que han mantenido abiertas puertas y ventanas a otras realidades, haciendo las veces de puentes, de hilos sutiles, entretejiendo la vida con la de otras latitudes a la manera de una tenue red que puede suponerse exigua, en comparación con el calibre de la tragedia. Quizás sean en efecto tan solo pequeños gestos, palabras, objetos, imágenes, sonidos, que no hacen otra cosa que, de muy diversas formas, interpelar a la humanidad, a través de las aberturas al mundo exterior, persistentes, constantes. En palabras de Nancy:

[...] el mundo no es otra cosa que una red inacabable de puntos que remiten unos a los otros. Origen y fin, o por decirlo de otra forma, articulación del 
bis

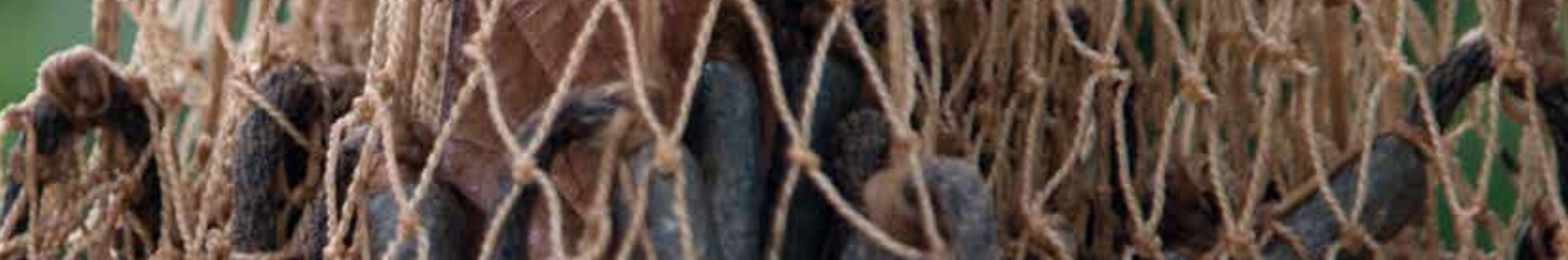
(2) 6.

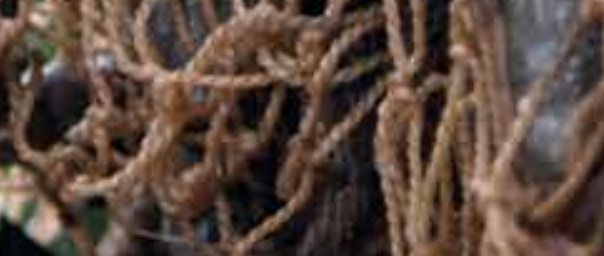
fis $y=1,0$ W S. 13 (3) 6.

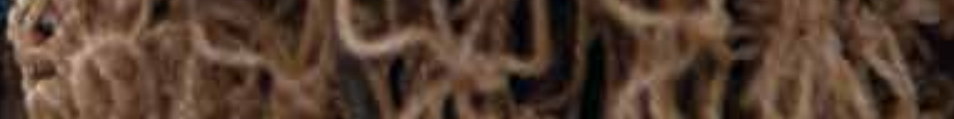

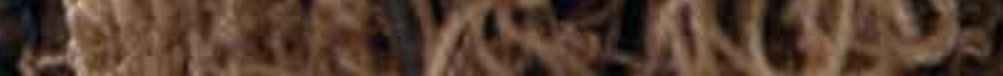
Hing

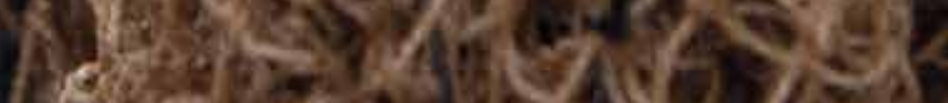

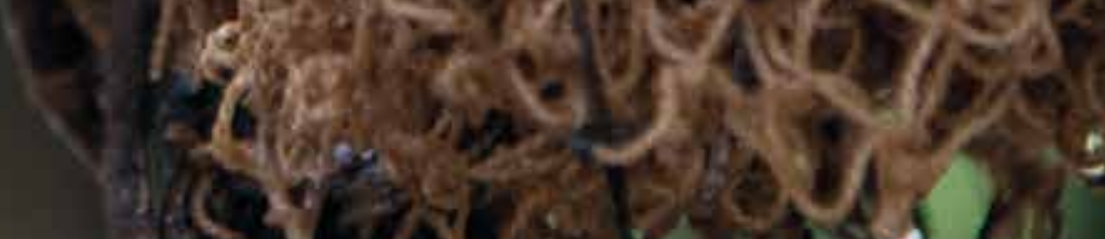

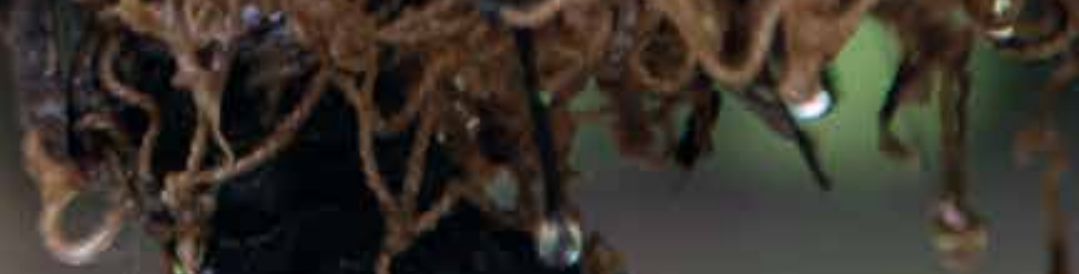
(1) 
mundo, o articulación de un mundo, porque el mundo es de hecho múltiple, multiverso o un pluriverso, como dicen ahora los físicos (Biblioteca Vasconcelos, 2015).

Eso pasa con el arte: parecería ajeno, inútil, y lo es. No tiene un uso práctico, pero hace posible respirar, así como pronunciar aquello que tiene el efecto de desencadenar y de dar un paso más, a otro lugar. Esa articulación con el resto del mundo marca la posibilidad para cada colombiano de relacionarse con las manifestaciones artísticas, cualquiera que sea su origen en el tiempo y el espacio, y tomar todo aquello que le brinde la posibilidad de hacer el recorrido del duelo a la supervivencia, con los otros ${ }^{15}$.

Semejante línea de acción no puede librarse a las fuerzas de cada individuo. Si el propósito es abrir el camino a las nuevas generaciones sin la guerra que padecieron sus antecesores, la magnitud del esfuerzo debe alcanzar a toda la nación y extenderse más allá del sistema escolarizado, incluyendo las instituciones de educación superior, desde alguna organización con miras que trasciendan los vaivenes políticos. Difícil, pero no imposible. Ubicar esta iniciativa fuera del sistema estatal permite que adopte la forma de la proposición y la promesa, la cadencia de un discurso que acoge, un discurso hospitalario ${ }^{16}$ con el dolor y la necesidad de la paz, no el de la imposición y la ideología, que amenazan las políticas estatales mejor intencionadas ${ }^{17}$.

Por ejemplo, y de vuelta a la reflexión de Didi-Huberman, una organización de esta naturaleza podría preguntarse: ¿Y si una tumba peculiar no recogiera un cuerpo sino acogiera su memoria, la suya y la de tantas otras víctimas? ${ }^{18}$. Un lugar dedicado a la memoria que provea una ubicación concreta, física y precisa a los dolientes, a la manera de un resquicio que se abre en la búsqueda de lo que está más allá del fin de las hostilidades, donde el arte pueda colarse y permear. Quizás una convocatoria a jóvenes arquitectos, acompañados por profesionales experimentados que hagan las veces de mentores, para diseñar y construir edificaciones en lugares emblemáticos donde honrar la memoria de los asesinados; los secuestrados; los desplazados; los desaparecidos, para iniciar en tiempo presente, la indispensable elaboración del duelo y para preservar esa memoria en las futuras generaciones. En esta formulación se ponen en juego la mencionada intervención del arte, como vehículo de lo inexpresable, y la de la educación en tanto proceso que pone en acto la transmisión de experiencia y conocimiento, de una generación a la siguiente, en torno a un propósito común: el de restañar desde todos los lugares posibles, las heridas infringidas por la guerra. Este podría ser uno.

\section{Imaginar: imagen-paz}

Si bien en el terreno académico, Colombia ha aportado importantes experiencias retomadas en otros países, entre ellos México ${ }^{19}$, hay una asignatura que permanece pendiente: la educación para la imagen. No es un pendiente solo en Colombia, también lo es en el resto del mundo.

Este señalamiento se refiere a in-corporar en el aprendizaje básico, desde prescolar, qué es y cómo relacionarse con la imagen. Prácticamente omnipresente en el terreno de la comunicación, de la vida privada de los sujetos y cotidiana de las sociedades, permea desde los gestos más familiares hasta los hechos que cambian el derrotero de la civilización occidental. Prácticamente todo pasa por la imagen, de ahí que aprender a pensarla y a relacionarse con ella constituye una de las habilidades indispensables para sobrevivir e interactuar con y en el mundo contemporáneo, porque la imagen no es tan solo visual, como lo plantea Nancy en L'image comme danse (Biblioteca Vasconcelos, 2015):

Lo que sin duda importa es la necesidad de pensar que no podemos no imaginar en el sentido de hacer imágenes, de habitarlas y de ser habitados por ellas. Esto quiere decir también en el sentido de danzar con ellas, danzar en ellas y que ellas danzan en nosotros.

Reconocer esa danza y darle lugar significa diseminar entre los nińos y jóvenes la capacidad para imaginar, para crear sus propias imágenes en los lenguajes pluriversos de la contemporaneidad, pero con una dirección: hacia la paz, lo que no significa excluir sus propios deseos ni descuidar otras posibilidades.

Es claro que la imagen, presente en el aula a través de múltiples formas y soportes, es un apoyo eficaz para el aprendizaje de toda clase de conceptos, habilidades, etc., pero no se aborda el aprendizaje de la imagen misma, aprehensible también como medio para la construcción de

15 La situación de los padres que han perdido a sus hijos a manos de la violencia, asesinados, desaparecidos o secuestrados, me remite especialmente a Mas allá del tiempo, de David Grossman.

16 En el sentido derridiano del término.

17 Una conmovedora, innovadora y hermosa muestra de lo que el diálogo y la colaboración, auspiciados por una organización, son capaces de crear a través del arte es la West-Eastern Divan Orchestra (http://www.westeastern-divan.org/).

18 Guardando las proporciones y distancias imprescindibles, el Vietnam Veterans Memorial diseñado por la arquitecta Maya Lin ofrece una muestra del poder de la representación para elaborar el dolor y para preservar la memoria. Imaginar algo así en Colombia, podría los nombres de guerrilleros, integrantes de grupos paramilitares y civiles, todos ahí representados sin distinción de bando, los colocaría en la misma categoría: la humana. En su obra también destaca What's missing?, memorial que se enfoca en generar conciencia en torno a la crisis actual de la biodiversidad y la pérdida de hábitats. (Ver: http://www.mayalin.com/).

19 Un ejemplo es el trabajo que han desarrollado en torno al modelo escolar multigrado. 
sentido $^{20}$. Volviendo a Nancy: "[...] la imagen es paradigma de toda forma artística, es la propiedad de un sentido tal como justamente no puede ser reunido, apropiado y determinado [de otra manera]". Es decir, a diferencia de otras imágenes impregnadas y creadas para comunicar algo: dar un mensaje, convencer, persuadir, moralizar, etc., la imagen que se hace cada cual de la obra artística es una apropiación, movimiento per se, de sentido, ya que pasa necesariamente por la percepción singular donde está jugada la propia historia; la relación con el sí mismo y con los otros, con el mundo; lo conocido y lo otro de cada uno, tocando esas fibras que permanecen en el margen de los empeños educativos, tal como lo formula Nancy:

De cara a la imagen en tanto que portadora o emisora de sentido, como se quiera decir, este sentido remite al sí mismo al remitir a otro. Tomemos el ejemplo del retrato. [...] El retrato no proporciona la semejanza con el original, su semejanza morfológica, sin abrir, al mismo tiempo, el sentido de esta semejanza por cuanto semejanza consigo mismo. [...] El deseo de imagen es el deseo de saber como deseo mismo, el deseo de imagen es precisamente que no se desea la re-presentación de la misma cosa ni de la cosa misma, sino que se desea ver cómo lo mismo puede retornar más allá, de otra manera, puede retornar a sí mismo alejándose, quizás infinitamente (Biblioteca Vasconcelos, 2015).

La semejanza consigo mismo es solo posible por y en la desemejanza/semejanza con el otro.

El deseo de saber, dice Nancy (Biblioteca Vasconcelos, 2015), anudado a la pulsión escópica, donde lo que se arremolina para la vida es la sed de la mirada del otro, que me mira desde el texto; desde la ecuación; desde el sonido; pero también desde la otra banca; desde el bando enemigo; vehiculiza en un camino de dos vías, la construcción de sentido:

Si la imagen es portadora del sentido del ser sí mismo [...] expone con la ausencia o con la irrealización de su supuesto modelo, precisamente el sentido de este en tanto que sí mismo... en tanto que sujeto, de tal manera que, lo que sea que se sea, deviene en la imagen, sujeto, es decir, definitivamente sujeto de sentido. Un sujeto es un sujeto de sentido.

Podríamos decir que no hay nombre propio, sino en la imagen, como imagen de lo propio y que una imagen tal está hecha de ritmo, pulsación, impulso, flexión, según las cuales lo propio se apropia.

En el nombre propio me reconozco y me distingo del otro, al tiempo que reconozco y distingo al otro de mí, en el suyo. Nombrar al otro sin creerlo, como decía Freud, solo en las posibilidades de matar o de ser asesinado.

Esta manera de abordar la imagen, de bordear las relaciones mirada-sujeto-arte-sentido conduce, por un lado, al reconocimiento del propio cuerpo, tan excluido de la vida escolar. En este sentido, a veces es sorprendente observar cómo las clases de danza han sobrevivido en las escuelas públicas, gracias a una consciencia que, quizás, podríamos llamar intuitiva: ¿Qué mejor manera de descubrirme y descubrir al otro que cuando nuestros cuerpos se funden con la música y se vuelven puro movimiento, flexión, ritmo, cadencia, pulsación, que puede repetirse una y otra, vez sin que nunca se regrese al mismo gesto? La danza vibra en la imagen y la imagen, danza:

Lucien de Samosade escribe en su Tratado de la danza: los autores que nos dan la genealogía más auténtica de la danza, dirán que data del origen mismo del universo y que es tan antigua como el amor. El curso de los astros, la conjunción de los planetas y de las estrellas fijas, su sociedad armoniosa, su admirable concierto, son los modelos de la primera danza (Biblioteca Vasconcelos, 2015).

Por otro lado, también conduce a desplegar desde los primeros intercambios en el espacio escolar, la inagotable diversidad del otro como parte de la propia capacidad para imaginar y crear imágenes distintas de las que se han construido a partir de la guerra, imágenes de paz con ese otro-que soy yo mismo- y con los demás. Poner, en el acto intencional de la educación, la frase lacaniana yo es otro, para mí mismo y para los demás. Afirmar, desde la creación de imágenes que danzan, que ese otro es también humano, significa exponerse y dejarse tocar, por el otro/enemigo/compatriota en la danza que transforma los cuerpos. El filo más significativo de este movimiento está en la recuperación de los nińos, muchos de ellos ahora jóvenes, reclutados por la guerrilla y el narcotráfico. No es un número que se destaque, pero sí la representación más álgida de lo que ha significado el conflicto para Colombia. Abrirles la posibilidad de que se imaginen otro futuro es, por tanto, crucial, ya que son el vértice donde coinciden el futuro de la población y del entorno, del hábitat.

Lo que se ha dejado en los márgenes ${ }^{21}$ persiste en la literatura; las artes visuales; el teatro; la música; el cine; la arquitectura; la danza; en suma, en el arte. Es la rosa de los vientos, donde el sujeto encuentra al mundo y este le devuelve otro ser y estar en él, siempre diverso, siempre en movimiento. Quizás esta sea la manera de acoger a las nuevas generaciones para no repetir los trayectos de sangre y dolor, cuyo terrible significado sigue marcándonos en la clave de lo innombrable, de lo atroz.

20 Ya el director de cine Roberto Rossellini había emprendido en los ańos 1970 la reflexión en torno a la imagen, específicamente la cinematográfica y la televisiva, en su ensayo Un espíritu libre no debe aprender como esclavo (1979).

21 Retomar el legado de Freud y Montessori, articulado a los planteamientos de teóricos contemporáneos como Didi-Huberman, Derrida y Nancy, por mencionar a los convocados en esta reflexión, abre líneas que apuntalan las coincidencias: "La primera línea verdadera de defensa contra la guerra es el hombre mismo...". 
Quizás construir la paz tendría que ser el sentido de una educación que se apoye en el arte y en la imaginación, como capacidad para crear imágenes, para - por fin- empezar a aprender a vivir. Una paz no solo para Colombia, sino para la especie y para nuestro planeta. ¿Conseguirían salvarlo las nuevas generaciones, así dotadas para la construcción de sentido? Quizás por esa posibilidad, la cifra de nuestra esperanza es Colombia.

$$
\begin{array}{r}
\text { La paz no se hace para que haya una justicia plena y completa. La } \\
\text { paz se hace para olvidar el } \\
\text { dolor pasado, para disminuir el dolor presente y para prevenir el dolor } \\
\text { futuro. } \\
\text { Héctor Abad Faciolince (2016). }
\end{array}
$$

\section{Referencias bibliográficas}

Abad Faciolince, H. (2016). Ya no me siento víctima. El pais. Recuperado de: http://cultura.elpais.com/cultura/2016/09/01/babelia/1472748478_962352.html

Biblioteca Vasconcelos [BV Vasconcelos] (enero de 2015). La imagen-danza. Por Jean Luc Nancy. Videoconferencia para el Coloquio "Las tres eras de la imagen”, Ciudad de México. [Archivo de video]. Recuperado de: https:// www.youtube.com/watch?v=g5LBm6IZStE

Claramonte, V. (26 de septiembre de 2013). ¿Qué es el ecocidio? Recuperado de: http://quecomoquien.republica.com/actualidad/que-es-el-ecocidio.html

Derrida, J. y Dufourmantelle, A. (2000). La hospitalidad. Buenos Aires: Ediciones de La Flor.

Derrida, J. (2004). Entrevista. Estoy en guerra conmigo mismo. Recuperado de: http://serbal.pntic.mec.es/ -cmunoz11/entrevista37.pdf

Didi-Huberman, G. (2010). Lo que vemos lo que nos mira. Buenos Aires: Manantial.

El Espectador. (8 de junio de 2016). Las cifras sobre los nińos y la guerra. Recuperado de: http://colombia2020.elespectador.com/pais/las-cifras-sobrelos-ninos-y-la-guerra

Expansión. (4 de diciembre de 2014). Peña Nieto llama a "superar" el dolor del caso Ayotzinapa. Recuperado de: http://expansion.mx/nacional/2014/12/04/ pena-nieto-guerrero-visita-plan-seguridad-ayotzinapa-43-normalistas

Freud, S. (1915). Obras completas. De guerra y muerte. Temas de actualidad. Tomo XIV. Buenos Aires: Amorrortu Editores.

Freud, S. (1917). Obras completas. Duelo y melancolía. Tomo XIV. Buenos Aires: Amorrortu Editores.

Grossman, D. (2011). Más allá del tiempo. Barcelona: Random House Mondadori, S.A.

Hubard, J. (2006). Sangre. Notas para la historia de una idea. México: Ortega y Ortíz editores.

Hubard, J. (1933). Obras completas. ¿Por qué la guerra? Einstein y Freud. Tomo XXII. Buenos Aires: Amorrortu Editores.

Lacan, J. (1981). Escritos I. México: Siglo XXI Editores.

Matamoro, B. (30 de noviembre de 2003). Pensar después de Auschwitz. Recuperado de: www.letraslibres.com/mexico-espana/pensar-despuesauschwitz

Ortega E., G. (2006). Un reencuentro con la esencia Montessori. México: Perspectiva Digital.

Revista Semana. (12 de febrero de 2015). Al fin, ¿̨cuándo empezó la guerra en Colombia? Recuperado de: http://www.semana.com/nacion/articulo/ cuando-empezo-la-guerra-en-colombia/417710-3
Rieff, D. (3 de septiembre de 2016). El caso de Bosnia no sirve para Siria. El pais. Recuperado de: http://internacional.elpais.com/ internacional/2016/09/02/actualidad/1472812684_542805.html

Rossellini, R. (1979). Un espiritu libre no debe aprender como esclavo. Barcelona: Editorial Gustavo Gili.

Ruiz, S. (5 de septiembre de 2012). Freud - Epistolario - Carta 178 - A María Montessori. Recuperado de: http://www.dos-teorias. net/2012/09/Carta-178-a-Maria-Montessori.html

Steiner, G. (2000). Antígonas. Barcelona: Editorial Gedisa.

Steiner, G. (2008). Los libros que nunca he escrito. Madrid: Siruela.

\section{Web}

Barber Samuel, Adagio para cuerdas, opus 11, https://www.youtube.com/watch?v=lKrxPTePXEQ

Pärt Arvo, Spiegel im spigel,

https://www.youtube.com/watch?v=FZe3mXlnfNc

\section{Verónica Vázquez-Cangas}

Licenciada en Pedagogía, cursó la Maestría en Teoría Crítica en 17 Instituto de Estudios Críticos. Durante los últimos ocho años se ha dedicado a la investigación educativa, en colaboración con el Consejo Nacional de Fomento Educativo, organismo que ha publicado sus trabajos, y con Worldfund, en su diplomado LISTO, como coach (acompañamiento educativo) de directivos de escuelas públicas del Sistema de Educación Básica mexicano. También se ha desempeńado como editora y traductora. verovcangas@gmail.com

Artículo recibido el 2 de septiembre de 2016 y aceptado el 30 de septiembre de 2016 
